\title{
Morphology of human endometrial explants and secretion of stromal marker proteins in short- and long-term cultures
}

\author{
Nick A. Bersinger • E. M. Genewein • O. Müller • \\ H. J. Altermatt • B. McKinnon • M. D. Mueller
}

Received: 9 July 2009 /Accepted: 28 August 2009 /Published online: 18 September 2009

(C) Springer-Verlag 2009

\begin{abstract}
Human endometrial tissue is frequently biopsied under surgical and laparoscopic procedures for the investigation of infertility, abdominal, or menstrual pain. These symptoms often but not always are the consequence of endometriosis, which is characterised by the growth of endometrial tissue outside the uterine cavity and affecting $8-10 \%$ of women during the fertile age. First-line treatment is often by surgery. Biopsied endometrial tissue is not only used for immunohistochemical examination but has also been cultured in vitro. Explant culture systems maintain the three-dimensional structure of the tissue, but so far no morphological validation studies are available for the stromal cells which are responsible for the production of hormones and inflammatory cytokines in the endometrium. We have documented, by transmission electron microscopy, the morphological alterations of stromal cells in short-
\end{abstract}

N. A. Bersinger $\cdot$ E. M. Genewein · M. D. Mueller

Department of Obstetrics and Gynaecology, University of Berne,

Berne, Switzerland

O. Müller

Department of Anatomy, University of Berne,

Berne, Switzerland

H. J. Altermatt

Department of Pathology, University of Berne,

Berne, Switzerland

B. McKinnon

Department of Clinical Research, University of Berne,

Berne, Switzerland

N. A. Bersinger $(\square)$

University of Berne, Endometriosis and Reproductive Medicine,

DKF Murtenstrasse 35,

CH-3010 Berne, Switzerland

e-mail: nick.bersinger@dkf.unibe.ch
(12 h) and long-term (7 days) cultures of endometrial explants biopsied in the postovulatory phase. The production of prolactin, a stromal cell marker, was determined. We found that the morphological integrity of these cells was starting to be disrupted from as early as $12 \mathrm{~h}$ in culture. Some stromal cells, however, developed into predecidual cells. After $96 \mathrm{~h}$, a large fraction of the cell population was necrotic, and after 7 days, the cytoplasm had disappeared. In presence of progesterone, the decay of stromal cell integrity was slowed down. The release of prolactin and IGF-binding protein-1 during culture followed the morphological pattern. We conclude that the explant culture model is viable for not more than $48 \mathrm{~h}$ in vitro for stromal cells, but that this interval can be prolonged by the addition of progesterone which initiates decidualisation.

Keywords Endometrium · Stromal cells · Explant culture · Transmission electron microscopy

\section{Introduction}

Surgically removed endometrial explants are often used culture systems for investigations in gynaecologic endocrinology and immunology. These systems maintain their three-dimensional structure and are competent for the de novo synthesis of endometrial proteins. The morphological validation for epithelial cells in explants cultured (for more than 4 days) has been provided by Dudley et al. [1], but no such validation has been given on stromal cells neither for morphological criteria nor for the specific production of biochemical markers.

The aim of this study was the documentation of morphological alterations of stromal cells and the analysis of the correlation between these and the secretion of 
stromal marker proteins prolactin (PRL) [2, 3] and insulinlike growth factor-binding protein-1 (IGF-bp1) $[4,5]$ in short-term $(12 \mathrm{~h})$ and long-term (up to 7 days) cultures of endometrial explants of the postovulatory phase. Short- and long-term cultures as defined by the time intervals given above were assessed by light and electron microscopy.

\section{Materials and methods}

This project focused on the morphology of endometrial explants after culture; the major endpoint of the study was the transmission electron microscopic aspect of the epithelial and particularly, the stromal cells at scheduled times (after 12, 24, 48, 96, and $168 \mathrm{~h}$ in culture). The production of the stromal marker proteins prolactin and IGF-bp1 was determined as an accompanying measure only. Progesterone-stimulated cultures were run as positive and negative controls, respectively.

Endometrial tissues from three nulliparous women were taken, in the postovulatory phase of a normal cycle, after hysterectomy performed for benign reasons. Absence of endometriosis was demonstrated histologically, no hormonal treatment was given, and informed consent was obtained from the patients. Preconditions were known infertility, regular cycle, and no substitution of hormones. The cycle phase and ovulation were ascertained by the determination of progesterone in a serum collected at the time of surgery. The tissue was dated according to the criteria of Noyes [6].
Fragments of $2-3 \mathrm{~mm}^{3}$ were cultured in $2 \mathrm{~mL}$ Dulbecco's modified Eagle's medium (DMEM) with added glutamine and antibiotic/antimycotic, both to $1 \% v / v$ from stock solutions (GIBCO-Invitrogen, Paisley, Scotland) under 5\% $\mathrm{CO}_{2}$ in air. After 12, 24, 48, 96, and $168 \mathrm{~h}$, an aliquot of explant was examined by light microscopy after fixation in $100 \%$ ethanol and by transmission electron microscopy after fixation in $3 \%$ glutaraldehyde. At the same time, an aliquot of the conditioned supernatant was removed and stored at $-30^{\circ} \mathrm{C}$ for the subsequent determination of the stromal cell-specific markers prolactin by dissociationenhanced lanthanide fluoroimmunoassay (Delfia ${ }^{\circledR}$, Wallac Oy, Finland) and of IGF-bp1 by a microplate enzyme immunoassay purchased from Bioserv, Rostock, Germany. Positive stimulation control cultures were run in the presence of progesterone $(200 \mathrm{nM})$.

\section{Results}

\section{Epithelial cells}

The morphological configuration of epithelial cells (cell layer with microvilli, ciliae, and nucleus) was found to remain intact until $96 \mathrm{~h}$ in culture. Thereafter, apoptotic alterations in the nucleus and cytoplasm were observed. Lipid granula were seen early after the setting up of the culture. This is shown in Fig. 1 (a: before culture; b, c: after 24 and $96 \mathrm{~h}$ in culture, respectively).
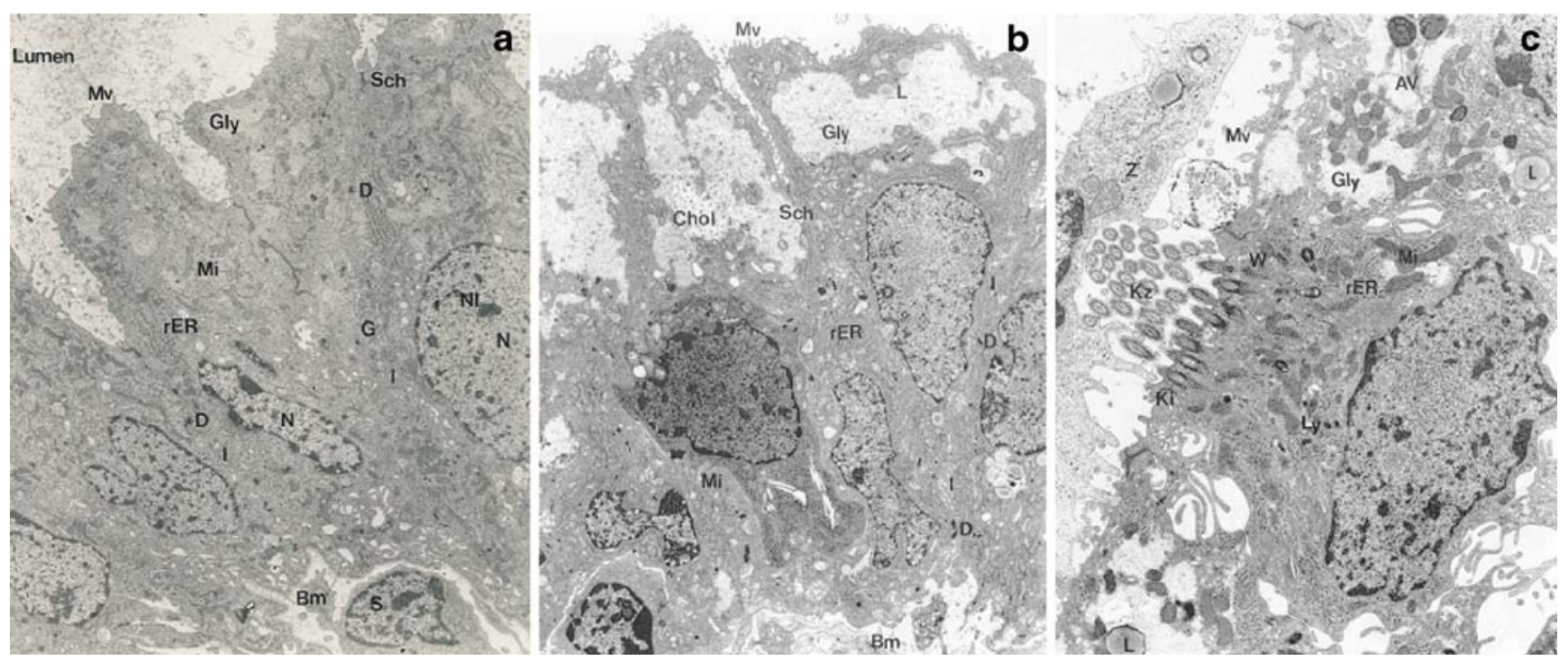

Fig. 1 Endometrial epithelial cells. a Intact cell at the time of sampling. Cellular borders are clearly visible, but the cells are connected through interdigitations $(I)$ and desmosomes $(D) . N$ nucleus, $N l$ nucleolus, $\mathrm{Mi}$ mitochondria, $r E R$ endoplasmatic reticulum, $G$ Golgi apparatus, Gly small deposits of glycogen, $B m$ basement membrane, $S$ stromal cell. b
Appearance of lipid granula in epithelial cells after $24 \mathrm{~h}$ in culture. $M v$ microvilli, Chol crystallised cholesterol. c Epithelial cell with cilia $(\mathrm{Kz})$ after $96 \mathrm{~h}$ in culture. $A V$ autophagic vacuole, $L y$ lysosomes, $L$ lipid deposit. Magnification, $\times 7,650$ 
Stromal cells

\section{Culture without supplements}

The morphological integrity of stromal cells (Fig. 2a) was disrupted early; already after $12 \mathrm{~h}$ of culture dilatation of rough endoplasmatic reticulum, condensation of nuclear chromatin and the appearance of apoptotic vesicles were noted (Fig. 2b). Nevertheless, some stromal cells were found to develop into predecidual cells as identified by the presence of glycogen storage vesicles and lipid droplets, an increased cytoplasmic volume and a higher number of cell contacts (Fig. 2c). After $96 \mathrm{~h}$ of culture, glycogen storage vesicles are still visible (Fig. 2d), but a large fraction of the stromal cell population was necrotic. After 7 days in culture, however, the stromal cells were degenerated by necrotic and apoptotic events, and the cytoplasm had disappeared (Fig. 2e). At this stage, the epithelial cells were still in contact with each other, but this was beginning to loosen, and the number and size of the lipid droplets had increased. This is shown in Fig. 3 which was taken at the intersection of the two cell types but with partial disappearance of the basal membrane.

The release rate of the stromal markers into the medium during culture followed the morphological pattern. Although prolactin concentration increased in the supernatant up to

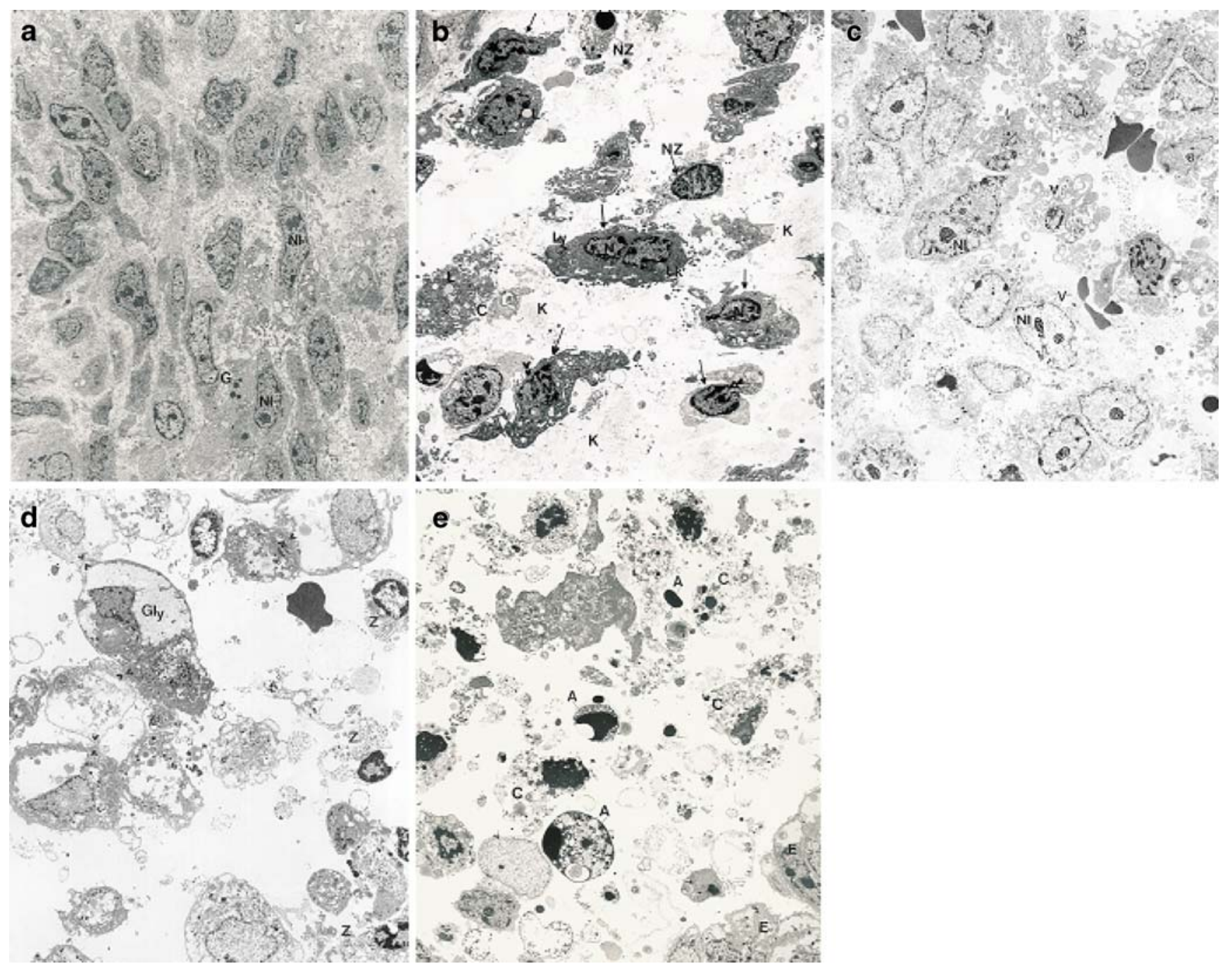

Fig. 2 Endometrial stromal cells. a Intact cell at the time of sampling. The cell membrane is intact but intercellular contact is scarce. Occasional granula of unknown origin, but no lysosomes or lipid deposits can be seen. b Stromal cells after $12 \mathrm{~h}$ in culture. First signs of degenerative processes can be observed. Nuclear invaginations and chromatin densification at the borders (arrows) have increased, and the matrix is partially dissolved. Lysosomes $(L y)$ and lipid deposits $(L k)$ are visible. c Stromal cells after $48 \mathrm{~h}$ in culture. Vacuoles $(V)$ and glycogen deposits have increased. Nucleoli $(N l)$ are prominent and structured. d Stromal cells after $96 \mathrm{~h}$ in culture. Large glycogen deposits are signs of decidualisation in the surviving cells, while the majority of cells is necrotic or apoptotic (Z). e Stromal cells after 7 days in culture. Large scale degeneration through apoptotic and necrotic processes. The cytoplasm $(C)$ has dissolved, and apoptotic bodies are separating from the cells. The cells at the bottom right $(E)$ are epithelial cells with glycogen inclusions. Magnification, $\times 3,550$ 


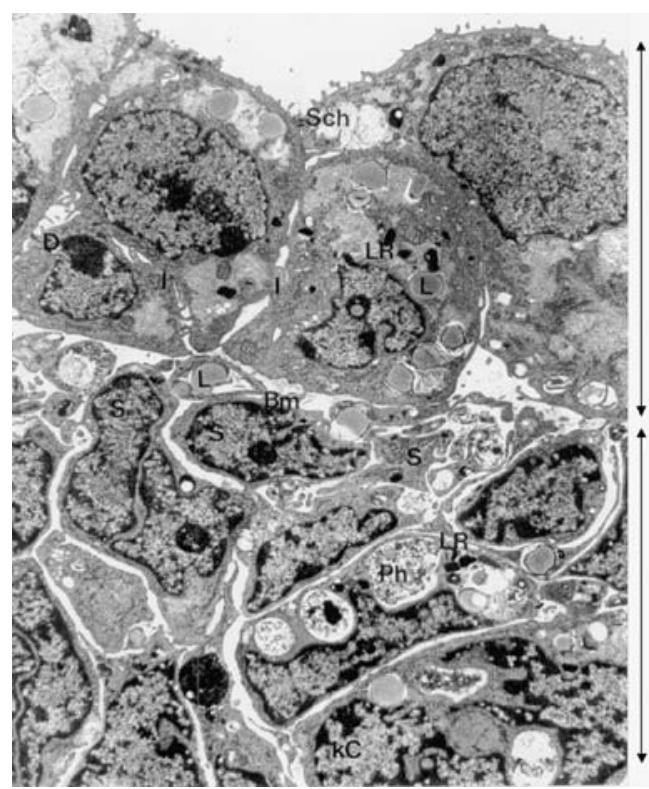

Fig. 3 Epithelial and stromal cells after 7 days in culture. Epithelial cells make up the top half of the panel (arrow at right); they are still loosely associated but the connexions between them $(I, D$, as shown in Fig. 1a) have become scarce. Lipid inclusions $(L)$ and lysosomal remains $(L R)$ have further increased in size. The basal membrane $(B m$, separating the two cell types through the middle of the panel) is only partially visible. The bottom half of the panes (arrow at right) shows degerated stromal cells, with condensed chromatin $(k C)$, phagosomes $(P h)$, and lysosomal remains. Magnification $\times 7,650$
$96 \mathrm{~h}$ in culture (Fig. 4a), the production rate per unit time of the hormone was highest after $12 \mathrm{~h}(4.07 \pm 2.00 \mathrm{pg} / \mathrm{mL} / \mathrm{h}$, mean \pm standard deviation) and decreasing thereafter $(3.14 \pm 1.37 \mathrm{pg} / \mathrm{mL} / \mathrm{h}, N=6$, Fig. $4 \mathrm{~b})$. The release rate of IGF-bp1 (Fig. 4d) peaked between $24(14.4 \pm 8.0 \mathrm{pg} / \mathrm{mL} / \mathrm{h})$ and $48 \mathrm{~h}(14.0 \pm 9.7 \mathrm{ng} / \mathrm{mL} / \mathrm{h}, N=4)$ and similarly declined thereafter.

\section{Culture in presence of progesterone}

The addition of progesterone results in the in vitro decidualisation of endometrial stromal cells. We have added progesterone $(200 \mu \mathrm{M})$ to our cultures and found that the decay of the stromal cell tissue seen above was considerably slowed down. Figure 5a shows stromal cells under decidualisation after 7 days in culture with progesterone. After this incubation period, epithelial cells also seem to be in better contact with each other, through desmosomes and interdigitations, in presence of the hormone (Fig. 5b) than in its absence (Fig. 3), and the basal membrane is present. This protection of the morphological features by progesterone was due to an inhibition of apoptosis as indicated by a decrease in terminal deoxynucleotidyl transferase-mediated dUTP nick end labelling (TUNEL) signals (not shown).

In presence of progesterone, the release of prolactin (Fig. 4c) and IGF-bp1 (Fig. 4d) was strongly increased. Peak production rates per unit time were reached after 48 and $96 \mathrm{~h}$ in culture for prolactin and IGF-bp1, respectively,
Fig. 4 Marker production by cultured endometrial stromal cells. a Concentration (accumulation) of PRL in the supernatant; six cultures, each in duplicate. $\mathbf{b}$ PRL production rate per hour, showing the constant decrease with time in culture. c PRL concentration (accumulation) in presence of progesterone $(200 \mathrm{ng} / \mathrm{mL})$; note the difference in scale compared to the control experiment without progesterone (a). d IGF-bp1 production by cultured endometrial stromal cells. The graph shows the concentration (accumulation) of IGF-bp1 in the supernatant (two cultures, each in duplicate). No progesterone added (open circles), culture in presence of progesterone (closed circles, $200 \mathrm{nM})$

\section{Prolactin concentration ( $\mathrm{pg} / \mathrm{mL}$ )}

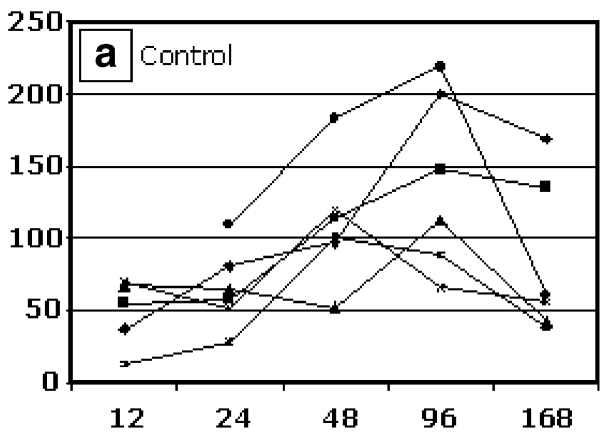

Prolactin concentration ( $\mathrm{pg} / \mathrm{mL}$ )

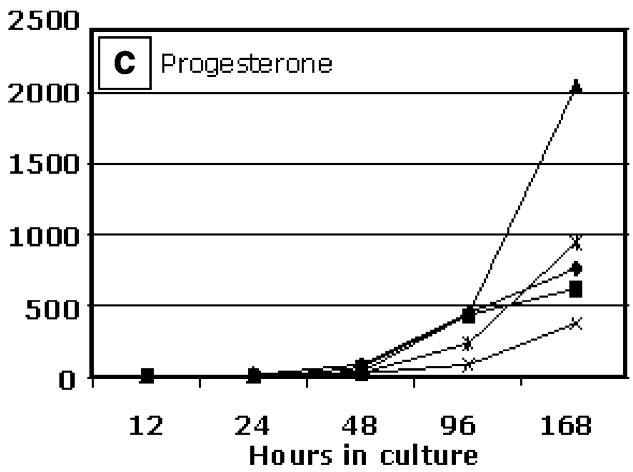

\section{Prolactin release rate $(\mathrm{pg} / \mathrm{mL} / \mathrm{hr})$}

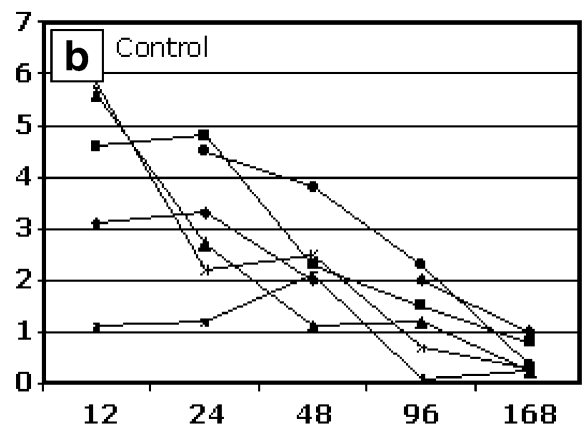

IGF-bp 1 concentration ( $\mathrm{ng} / \mathrm{mL}$ ) 100

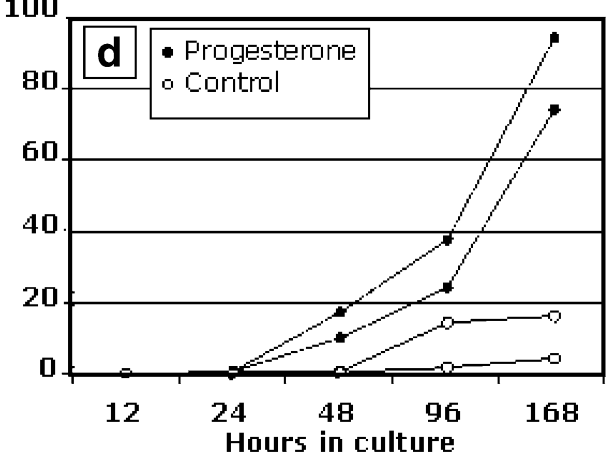


Fig. 5 Morphology of stromal and epithelial endometrial cells after culture in presence of progesterone $(200 \mathrm{nM})$. a Decidualised stromal cells after 7 days in culture in presence of $200 \mathrm{nM}$ progesterone. Wellpreserved cells with normally configured nuclei $(N)$ containing glycogen and lipid deposits. Magnification, $\times 7,600$. b Epithelial cells after 7 days in culture in presence of $200 \mathrm{nM}$ progesterone. In contrast to the control culture without the steroid hormone (Fig. 3), the intercellular contacts are still well established even after the long culture period. For abbreviations, see legend to Fig. 1. Magnification, $\times 13,400$
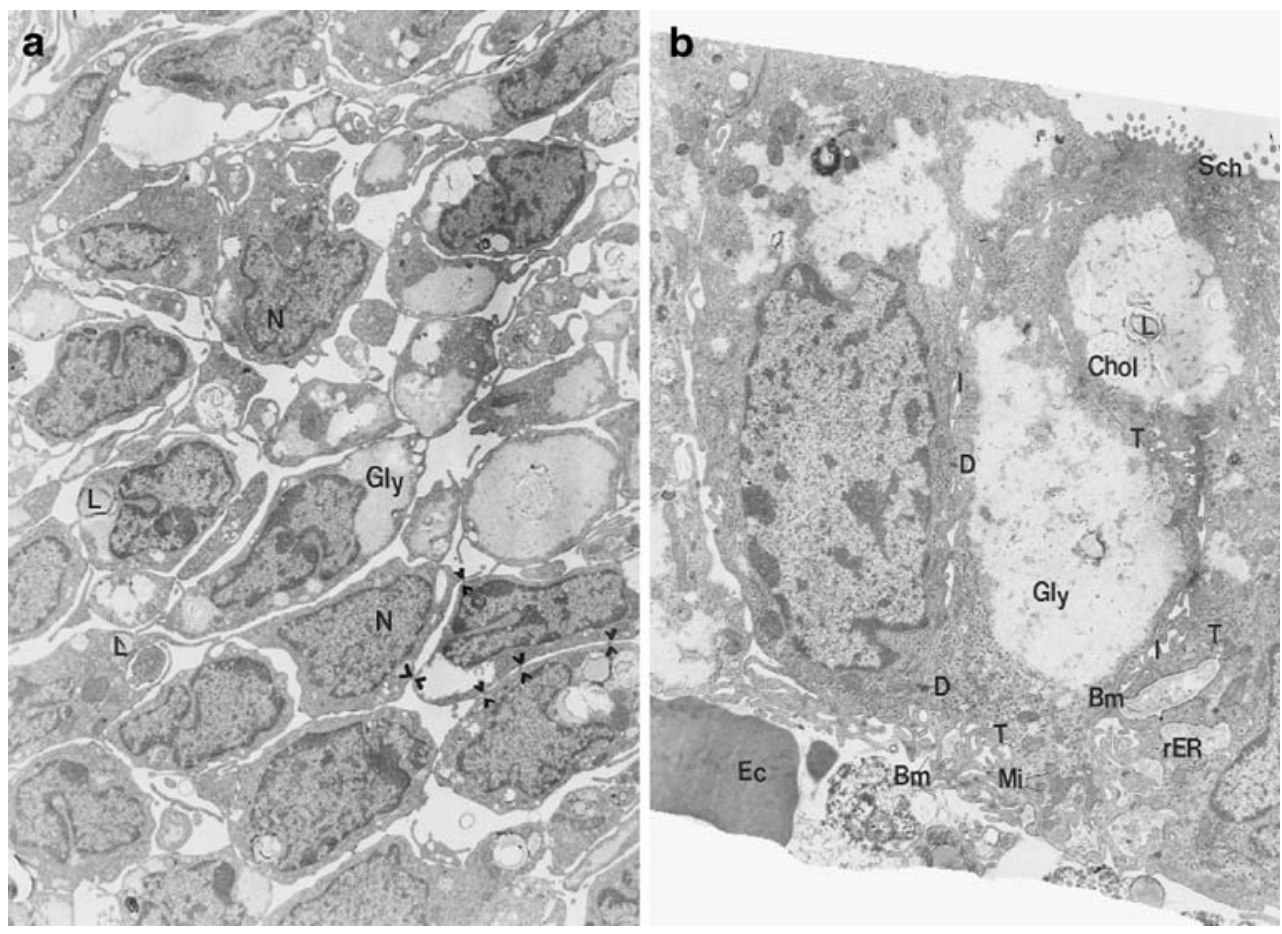

and their concentrations in the supernatant continued to rise after 7 days in culture (Fig. 4c, note the difference in scale when comparing to the control, Fig. 4a).

\section{Discussion}

Our observations concerning the morphology of epithelial cells correspond to the published validation study [1] where the viability of these cells over 4 days was documented. Later in the course, apoptotic features, like the condensation of nuclear chromatin and autophagy, are seen. The occurrence of lysosomes, glycogen, and lipid bodies increased during culture time, which is meant to be a sign of degeneration. On the other hand, we detected an increased number of lipid granules in epithelial cells stimulated by progesterone. According to Dallenbach [7], this feature seems to be a sign for increased cell activity; the epithelial cells stay intact for a longer time in culture than stromal cells do. The production of prolactin and IGF-bp 1 similarly rises after the addition of progesterone. At the beginning of the culture, proteins are secreted from apoptotic vesicles, as well as synthesised de novo by the cells, and accumulate in supernatant. After 48 and 96 h, prolactin and IGF-bp1 are destroyed by proteases released by necrotic cells. In spite of this consideration, further studies, e.g., with purified epithelial cells in primary culture, are required to clarify whether epithelial markers (e.g., glycodelin) also increase in vitro with the addition of progesterone and whether the development of lipid bodies due to progesterone is a truly stromal cell-mediated event. Stromal cells seem to be severely affected morphologically during the early culture phase by apoptotic features and later by excessive necrosis. The production of prolactin declined, probably due to proteases secreted by necrotic cells at the same time. Studies with a protease inhibitor should clarify this consideration. Despite the overall degenerative state, a fraction of stromal cells seems to develop into predecidual cells without the addition of progesterone. To our knowledge, this has not been described to date. The development of decidual cells during pregnancy (i.e., exposure to high progesterone levels), however, has been studied, and the induction of decidualisation of stromal cells, together with increased prolactin production, by progesterone was confirmed [4, 8-11]. A single short application of progesterone induces development of stromal cells to decidual cells [12]. In this study, we have identified areas with decidualised stromal cells in progesterone-added culture. Using light and transmission electron microscopy together with the TUNEL method, we could show that the tissue is protected in presence of progesterone and that stromal cells remain morphologically intact for an extended time. The inhibition of apoptosis by progesterone has been demonstrated previously [13]. Based on our observations, stromal cells are viable for 7 days in culture in presence of progesterone at $200 \mathrm{ng} / \mathrm{mL}$.

In conclusion, we have observed in this preliminary study that, in contrast to the validation study of Dudley [1], the endometrial explant system is limited by an early decay of stromal cells in the absence of added progesterone. Products of stromal cells, like prolactin and IGF-bp1, are detected in the supernatant of endometrial explant cultures, which could be due at least in part to early cell decay and the release of 
previously synthesised markers. However, as long as stromal cells show apoptotic features, the culture system is viable, and this seems to be the case for $48 \mathrm{~h}$. This interval can be prolonged by the addition of progesterone, which not only slows stromal cell decay but also stimulates the decidualisation of these cells. In the future and in an extension of this preliminary project, it would be interesting to compare the morphological observations in endometrial tissue from healthy (besides infertility), cycling women cultured under control, not oestrogen stimulated conditions (as done in this study) between different stages of the menstrual cycle, or between the absence or presence of oestrogen ( $17 \beta$-estradiol) in the culture. Moreover, as evidence is increasing that, in women suffering from endometriosis, there are significant differences between cases and healthy controls even in the eutopic (intrauterine) tissue, the project could be extended to the comparison of electron microscopic features as a function of the severity of endometriosis. This would, however, require the creation of different groups of patients and therefore, result in a large number of cultures and EM analyses to be performed and statistically analysed.

Conflict of interest There is no actual or potential conflict of interest in relation to this article.

\section{References}

1. Dudley DJ, Hatasaka HH, Branch DW, Hammond E, Mitchell MD (1992) A human endometrial explant system: validation and potential applications. Am J Obstet Gynecol 167:1774-1780
2. Riddick DH, Luciano AA, Kusmick WF, Maslar IA (1978) De novo synthesis of prolactin by human decidua. Life Sci 23:19131922

3. Tadokoro N, Koibuchi N, Ohtake H, Kawatsu T, Tanaka S, Ohkawa H, Kato Y, Yamaoka S, Kumasaka T (1995) Localization of prolactin and its receptor messenger RNA in the human decidua. Experientia 51:1216-1219

4. Morimoto Y (1988) Ultrastructural and endocrinological study of the human endometrium and decidua using the organ culture method. Acta Obstet Gynaecol Japon 40:201-208

5. Fay TN, Lindenberg S, Teisner B, Westergaard LG, Westergaard JG, Grudzinskas JG (1990) De novo synthesis of placental protein-14 (PP14) and not PP12 by monolayer cultures of glandular epithelium of gestational endometrium. J Clin Endocrinol Metab 70:515-518

6. Noyes RW, Hertig AT, Rock J (1950) Dating the endometrial biopsy. Fertil Steril 1:3-25

7. Dallenbach-Hellweg G (1981) Histopathology of the endometrium. Springer Verlag, 3rd edition

8. Csermely T, Demers M, Hughes EC (1969) Organ culture of human endometrium. Effects of progesterone. Obstet Gynecol $34: 252-259$

9. Daly DC, Maslar IA, Riddick DH (1983) Prolactin production during in vitro decidualisation of proliferative endometrium. Am J Obstet Gynecol 145:672-678

10. Maslar IA, Ansbacher R (1986) Effects of progesterone on decidual prolactin production by organ cultures of human endometrium. Endocrinology 118:2102-2108

11. Tabanelli S, Tang B, Gurpide E (1992) In vitro decidualisation of human endometrial stromal cells. J Steroid Biochem Mol Biol 42:337-344

12. Maslar IA, Ansbacher R (1988) Effect of short-duration progesterone treatment on decidual prolactin production by cultures of proliferative human endometrium. Fertil Steril 50:250-254

13. Rotello RJ, Lieberman RC, Lepoff RB, Gerschenson LE (1992) Characterisation of uterine epithelium apoptotic cell death kinetics and regulation by progesterone and RU486. Am J Pathol 140:449-456 